\title{
Evaluation of Nursing Students' Communication Abilities in Clinical Courses in Hospitals
}

\author{
Mahnaz Shafakhah ${ }^{1}$, Ladan Zarshenas ${ }^{2}$, Farkhondeh Sharif ${ }^{3} \&$ Raheleh Sabet Sarvestani ${ }^{4}$ \\ ${ }^{1}$ Department of Nursing, School of Nursing and Midwifery, Student research Committee, Shiraz University of \\ Medical Sciences, Shiraz, Iran \\ ${ }^{2}$ Department of Mental Health and Psychiatric Nursing, School of Nursing and Midwifery, Member of quality \\ improvement in clinical education research center, Shiraz University of Medical Sciences, Shiraz, Iran \\ ${ }^{3}$ Department of Mental Health and Psychiatric Nursing, School of Nursing and Midwifery, Community Based \\ Nursing and Midwifery Research Center, Shiraz University of Medical Sciences, Shiraz, Iran \\ ${ }^{4}$ Department of Nursing, School of Nursing and Midwifery, Fasa University of Medical Sciences, Fasa, Iran \\ Correspondence: Dr. Ladan Zarshenas, Assistant Professor, Department of Nursing, School of Nursing and \\ Midwifery, Member of quality improvement in clinical education research center, Shiraz University of Medical \\ Sciences, Shiraz, Iran. E-mail: zarshenas@sums.ac.ir
}

Received: October 8, 2014 Accepted: November 13, 2014 Online Published: January 25, 2015

doi:10.5539/gjhs.v7n4p323 URL: http://dx.doi.org/10.5539/gjhs.v7n4p323

\begin{abstract}
Background: Joint Commission on Accreditation of Healthcare Organizations (JCAHO) has established, improving communication as a priority for improving patient safety since 2006. Therefore, the present study aimed to evaluate nursing students' communication abilities to recognize their strengths and weaknesses in communication skills.

Method: This cross-sectional study was carried out in 2014. The study participants included all the nursing students who passed two semesters in Fatemeh School of Nursing and Midwifery in Shiraz, Iran. The students' communication skills were assessed using a self-administered questionnaire. Then, the data were entered into the SPSS statistical software (v. 16) and analyzed using both descriptive (mean and percentage) and inferential statistics (Pearson correlation and ANOVA).

Results: Among the 200 students who completed the questionnaires, $58 \%$ were female and $42 \%$ were male with the mean age of 21.79 years $(\mathrm{SD}=2.14)$. The results of Pearson correlation analysis demonstrated a significant correlation between the nursing students' clinical communication behavior scores and treatment communication ability scores $(\mathrm{P}<0.001)$. The findings demonstrated that most nursing students required improvement in their communication skills in both clinical communication behavior and treatment communication ability. Besides, a significant difference was observed among the students of different terms regarding clinical communication behaviors $(\mathrm{P} \leq 0.05)$, but not concerning communication abilities. Nursing students in higher semesters had better communication skills.

Conclusions: The results showed that nursing students in this university had a moderate ability in clinical and treatment communication. Thus, paying attention to standard education, curriculum revision, and adding some specific theoretical lessons for improving communication skills are mandatory during the bachelor's degree.
\end{abstract}

Keywords: communication, nursing, student

\section{Introduction}

Communication is a vital element in nursing in all areas of activity, including prevention, treatment, rehabilitation, education, and health promotion (Kourkouta \& Papathanasiou, 2014 ). If nurses want to provide a qualified professional care, they have to be able to communicate well with patients, families, physicians, and other healthcare teams. Communication with patients is the most important aspect of professional nursing whose failure can lead to ineffectiveness of nurses' and other healthcare teams' potentials (J. E. Liu, Wong, Xue, \& Xu, 2007). Clinical communication skill is defined as communicating with patients, their family members, and other healthcare teams (J. F. Xie, Ding, Wang, \& Liu, 2013).Literature showed that good communication could increase patient satisfaction and trust among nurses, patients, and family members and also decrease the patients' 
blood pressure, pain, and anxiety during hospitalization (Reader, Flin, \& Cuthbertson, 2007). On the other hand, failure in communication could lead to stress, errors in diagnosis, decrease of patient participation in care plans and information exchange, poor outcomes, and even death (Fallowfield, Saul, \& Gilligan, 2001; Greco, Spike, Powell, \& Brownlea, 2002; Leonard, Graham, \& Bonacum, 2005; Meyer \& Arnheim, 2002). Recent studies showed that most medical errors were not really due to defect in medical technologies or negligence of healthcare providers; rather, they were absolutely related to ineffective communication between patients and physicians (Xie et al., 2013).

Despite the effect of communication skills on the quality of nursing care and patient improvement and participation in care, the results of different researches showed that nurses were not successful in communicating with patients and families (Chant, Jenkinson, Randle, \& Russell, 2002; McCabe, 2004; A. R. Zamani, Shams, Farajzadegan, \& Tabaeian, 2003; A. Zamani, Shams, \& Moazzam, 2004). Nurses communicated with patients for a very short period of time, they talked with patients superficially, and the communication was always about physical needs and little attention was paid to psychological needs (Krautscheid, Scholarship 2008; Sabet Sarvestani, Moattari, Nikbakht, Momennasab, \& Yektatalab, 2013). This problem is evident in nursing students, too. Zay et al. in a descriptive study showed that $88.1 \%$ of nursing students had poor skills in clinical, treatment, and interpersonal communication (Xie et al., 2013) . Besides, Sabzevari et al. showed that nurses' performance was almost favorable in starting the conversation and interactive skills, intermediate in following the problems and describing the current disease, and completely inappropriate in terminating the conversation (Sabzevari, Soltani Arabshahi, Shekarabi, \& Koohpayehzadeh, 2006).

Communication skills used in nursing and treatment communication behaviors are the most important skills that aim to resolve some main problems of communicating (Swinny \& Brady, 2010). Expressing support, providing information and feedback, giving hope to patients, and helping them cope with anxiety are some examples of treatment communication behaviors (Elizabeth, 2006).

Since communication between nurses and patients is a core principle in patient care and Joint Commission on Aaccreditation of Health care organizations (JCAHO) has established improving communication as a priority for improving patient safety since 2006 (Schroeder, 2006), recognition of nursing students' strengths and weaknesses in this regard is a priority for planning and modification in future. Therefore, the present study aims to evaluate and analyze different communication skills in nursing students.

\section{Method}

This cross-sectional study was carried out in Fatemeh (P. B. U. H) School of Nursing and Midwifery in Shiraz, Iran in 2014. The study participants included all the nursing students who had passed two clinical semesters in this school. The study was approved by the Research and Ethics Committee of Shiraz University of Medical Sciences and after an explanation of the study objectives, written informed consent for taking part in the study were obtained from all the students. The nursing students' communication skills were assessed using a self-administered questionnaire which consisted of three different parts. The first part of the questionnaire was related to the demographic data. The second part which involved treatment communication behaviors contained 9 items and 42 subscales. These 9 items included sharp listening, effective transfer of information, participation, establishing harmonized relationships, preparation for communication, effective improvement, process control, ending communication work, and self-evaluation. The 42 subscales were responded through a 5-point Likert scale ranging from 1 (never) to 5 (always), but the last question was self-evaluation and scored as well, approximately good, no idea, approximately week, and week. The last part of the questionnaire was related to clinical communication behaviors and included the following 8 items: communication with schoolmates in the clinical setting and university, clinical teachers, theoretical teachers, patients' family members, doctors, and other personnel. These items were scored through a Likert scale ranging from 1 (very comfortable) to 4 (very hard), but the last question was self-evaluation and scored as very well, well, no idea, weak, and very weak. After all, the data were entered into the SPSS statistical software (v. 16) and analyzed using descriptive and inferential statistics. Besides, $\mathrm{P}<0.05$ was considered as statistically significant.

\subsection{Reliability and Validity}

At first, the original Japanese version of the questionnaire (Xie et al., 2013) was translated into the target language (Persian) by a bilingual translator. Then, the psychometric characteristics of the translated version were evaluated using two methods of random probe and committee approach. In random probe, the researcher asked 20 individuals of the target population to answer the following questions: "What do you think the question is about?" and "What do you mean?" and also determine if any item of the translated form was ambiguous or not understandable. If discrepancies were found, the related items were revised. In committee approach, on the other hand, 6 experts reviewed the clarity and linguistic appropriateness of the translated version of the questionnaire 
and the necessary changes were applied. The face and content validity of the items were examined with the help of 6 experts in the field of nursing and psychometric. Also, the items were assessed with respect to comprehension, ambiguity, clarity, and relation to the study objectives. In addition, the reliability of the questionnaire was confirmed using Cronbach's alpha test.

\section{Results}

In this study, 200 students in practical clinical training completed the questionnaires. The mean age of the participants was 21.79 years $(\mathrm{SD}=2.14), 58 \%$ were female, and $42 \%$ were male. Other demographic characteristics of the participants have been presented in Table 1.

Table 1. Characteristics of the participants

\begin{tabular}{lll}
\hline Characteristics & Number & \% \\
\hline Age (year) & 186 & 93 \\
$18-24$ & 14 & 7 \\
$25-33$ & & \\
Gender & 84 & 42 \\
Male & 116 & 58 \\
Female & & \\
Semester & 36 & 18 \\
2 & 46 & 23 \\
3 & 41 & 20.5 \\
4 & 24 & 12 \\
5 & 46 & 23 \\
6 & 7 & 3.5 \\
8 & & \\
Standard education & 72 & 36 \\
Yes & 131 & 65.5 \\
No & Mean & SD \\
Scores & 78.60 & 1.34 \\
Clinical communication skills & 12.19 & 0.23 \\
Treatment communication skills & & \\
\hline
\end{tabular}

The participants' mean scores of clinical communication and treatment communication abilities were $78.60 \pm 1.34$ and $12.19 \pm 0.23$, respectively. Besides, the result of students' self-evaluations demonstrated that $86.2 \%$ of the participants were "good" and "approximately good" in treatment communication skills and $85.2 \%$ were "good" and "very good" in clinical communication skills. Considering the clinical communication behaviors, the participants reported that they could communicate with their schoolmates $(95 \%)$, teachers $(88 \%)$, patients' family members $(88 \%)$, patients $(93 \%)$, nurses $(91 \%)$, and doctors $(72 \%)$ comfortably and very comfortably.

The results of Pearson correlation analysis demonstrated a significant correlation between the nursing students' clinical communication behavior scores and treatment communication ability scores $(\mathrm{r}=0.352, \mathrm{P}<0.001)$. Also, a significant correlation was observed between the students' educational semester and their clinical communication behavior scores $(\mathrm{r}=0.21)$ and treatment communication ability scores $(\mathrm{r}=0.132)$ (Table 2$)$. 
Table 2. Correlation between the clinical communication scores and treatment communication scores

\begin{tabular}{|c|c|c|c|c|c|}
\hline Factors & $\begin{array}{l}\text { Correlation and } \\
\text { P-value }\end{array}$ & $\begin{array}{l}\text { Treatment } \\
\text { skills }\end{array}$ & Communication & $\begin{array}{l}\text { Clinical } \\
\text { skills }\end{array}$ & Communication \\
\hline \multirow[t]{2}{*}{ Clinical communication skills } & Correlation coefficient & $0.352^{* * *}$ & & 1 & \\
\hline & P-value & $\leq 0.001$ & & & \\
\hline \multirow{2}{*}{$\begin{array}{l}\text { Treatment } \\
\text { skills }\end{array}$} & Correlation coefficient & 1 & & $0.352^{* *}$ & \\
\hline & P-value & & & $\leq 0.001$ & \\
\hline \multirow[t]{2}{*}{ Semester } & Correlation coefficient & $0.132^{*}$ & & $0.21^{*}$ & \\
\hline & P-value & $\leq 0.006$ & & $\leq 0.006$ & \\
\hline
\end{tabular}

*Note. Significant at $\alpha=0.05$.

** Significant at $\alpha=0.001$.

However, the results of one-way ANOVA showed no significant difference between the two sexes regarding clinical communication behavior scores and treatment communication ability scores. Nonetheless, a significant difference was observed among the students of different semesters concerning clinical communication behavior scores $(\mathrm{P}<0.05)$, but not regarding treatment communication ability scores (Table 3 ). The Cronbach's alpha of the questionnaire was 0.91 .

Table 3. Comparison of communication skills based on different variables

\begin{tabular}{lllll} 
& & Variables & F & P-value \\
\cline { 2 - 5 } & Clinical communication skills & Age group & 3.07 & $0.049^{*}$ \\
& Treatment communication skills & & 1.12 & 0.328 \\
& Clinical communication skills & Semester & 3.166 & $0.009^{*}$ \\
& Treatment communication skills & & 0.314 & 0.314 \\
& Clinical communication skills & Sex & 0.103 & 0.174 \\
& Treatment communication skills & & 0.347 & 0.952 \\
& Clinical communication skills & Standard education & 1.01 & $0.02^{*}$ \\
& Treatment communication skills & & 0.725 & 0.503 \\
\cline { 2 - 5 } *ote. Significant at $\alpha=0.05$. & & &
\end{tabular}

\section{Discussion}

Accurate communication is a principle for nursing care and some experts have referred to this skill as the heart of nursing care (Namdar, Rahmani, \& Ebrahimi, 2009). Therefore, it is imperative to teach communication skills to the nursing students who take care of patients in hospitals (Xie et al., 2013). Unfortunately, the present study findings demonstrated that most nursing students required improvement in their communication skills in both clinical communication behavior and treatment communication ability. Lambrini Kourkouta et al. (2014) stated that if nurses wanted to be successful in their work, they had to study communication and interpersonal relations through special courses and internships. They also needed to learn various aspects and applications of communication in various fields of nursing (Kourkouta \& Papathanasiou, 2014 ).

Our study revealed that nursing students in higher semesters had better communications skills. These determinations are consistent with those obtained in World Health Organization (WHO) survey which indicated that communication ability of the nurses who graduated from colleges or universities was significantly higher compared to those who received lower educational levels (WHO, 2009).

The notable finding in this study was that most nursing students had problems communicating with physicians, which is in agreement with other previous studies. In one study, among over 1,100 nurses responding to the survey, only $43 \%$ reported feeling satisfied with their relationships with physicians and $68 \%$ doubted that physicians understood nursing responsibilities (Sirota, 2007). Moreover, JCAHO reported that communication failures among professionals caused $70 \%$ of the 2,455 reported sentinel events, resulting in about $75 \%$ of the patients' death (Joint Commission on Accreditation of Healthcare Organizations Sentinal Event Statistics, 2004). 
Sirota T. (2007) indicated that nurses could improve their working relationships with physicians by continuing education, gaining specialty certifications, and participating in professional organizations, clinical research, conferences, and interdisciplinary committees (Sirota, 2007). Inter-professional education is another solution for this problem. Barr et al. (2000b) summarized the four main benefits of inter-professional education as follows: motivation to collaborate, change in attitudes and perceptions, cultivated interpersonal, group, and organizational relations, and established common value and knowledge bases (Barr, Freeth, Hammick, \& Association, 2000). Hence, inter-professional education program is recommended to be enhanced in countries worldwide.

Interestingly, the current study results revealed no statistically significant difference between the two sexes regarding communications abilities. However, Merchant K. (2012) showed a significant difference between the two sexes with respect to communication styles and practices (Karima, Fall 2012). Therefore, this issue is required to be further addressed in future studies. In addition, our study showed that the students who received education could communicate better with patients, their family members, and other personnel. This indicates the important of revision and addition of some communication skills courses in the nursing curriculum. To date, no communication skills courses have been considered during bachelor's degree education and this issue has been noted in only some lessons (Namdar et al., 2009). Thus, despite its importance, most nursing students did not learn communication skills before entering the clinical settings (Xie et al., 2013). Furthermore, the results of the present study showed a significant correlation between clinical communication skills and treatment skills scores, but this point has not been considered in our curriculums. Similar results were also obtained by Zay et al. (2012). Consistent with other studies, the current study researchers proposed that nursing communication skills could be improved through integrated teaching(J.-E. Liu, Mok, Wong, Xue, \& Xu, 2007; Xie et al., 2013). Although clinical setting affects the students' attitudes, skills, knowledge, and abilities to confront problems, it is not enough for them to learn accurate communications skills, and integrated teaching is mandatory (Henderson, Happell, \& Martin, 2007; J. Xie, Ding, Wang, \& Liu, 2012). Although this study was conducted on a large sample size, it relied on self-report measures, which was one of the limitations of the research. In addition, since this study was conducted on clinical nursing students in Shiraz, other universities are recommended to be evaluated and compared, as well. Moreover, given that communication ability is an important factor in health care teams, similar studies are suggested to be conducted on other healthcare personnel in hospitals.

\section{Conclusions}

Our study highlighted the importance of improving the students' treatment and clinical communication skills. The study also showed the necessity for curriculum revision and adding some specific theoretical lessons for improving communication skills during bachelor's degree education.

\section{Acknowledgments}

The authors are grateful for Ms. A. Keivanshekouh at the Research Improvement Center of Shiraz University of Medical Sciences for improving the use of English in the manuscript.

\section{References}

Barr, H., Freeth, D., Hammick, M., \& Association, B. E. R. (2000). Evaluations of interprofessional education: a United Kingdom review for health and social care.

Chant, S., Jenkinson, T., Randle, J., \& Russell, G. (2002). Communication skills: some problems in nursing education and practice. Journal of Clinical Nursing, 11(1), 12-21. http://dx.doi.org/10.1046/j.1365-2702.2002.00553.x

Elizabeth, A. (2006). Interpersonal relationships: professional communication skills for nurses. Elsevier Science Health Science Div, 29-30.

Fallowfield, L., Saul, J., \& Gilligan, B. (2001). Teaching senior nurses how to teach communication skills in oncology. Cancer Nursing, 24, 185-191. http://dx.doi.org/10.1097/00002820-200106000-00004

Greco, M., Spike, N., Powell, R., \& Brownlea, A. (2002). Assessing communication skills of GP registrars: a comparison of patient and GP examiner ratings. Medical Education, 36(4), 366-376. http://dx.doi.org/10.1046/j.1365-2923.2002.01175.x

Henderson, S., Happell, B., \& Martin, T. (2007). Impact of theory and clinical placement on undergraduate students' mental health nursing knowledge, skills, and attitudes. International Journal of Mental Health Nursing, (16), 116-125. http://dx.doi.org/10.1111/j.1447-0349.2007.00454.x

Joint Commission on Accreditation of Healthcare Organizations Sentinal Event Statistics (2004). Retirved from http://www.JCAHO.org. Accessed September 2006.

Karima, M. (Fall 2012). How men and women differ: gender differences in communication styles, influence 
tactics, and leadership styles. Senior Thesis CMC Senior Theses.Paper 513, Claremont McKenna College. Retrieved from http://scholarship.claremont.edu/cmc_theses/513

Kourkouta, L., \& Papathanasiou, I. (2014 ). Communication in nursing practice. Mater Sociomed, 26(1), 65-67. http://dx.doi.org/10.5455/msm.2014.26.65-67

Krautscheid, L. (Scholarship 2008). Improving communication among healthcare providers: preparing student nurses for practice. International Journal of Nursing Education, 5, e40.

Leonard, M., Graham, S., \& Bonacum, D. (2005). The human factor, the critical importance of effective teamwork and communication in providing safe care. Quality \& Safety in Health Care, 13, 85-90. http://dx.doi.org/10.1136/qshc.2004.010033

Liu, J.-E., Mok, E., Wong, T., Xue, L., \& Xu, B. (2007). Evaluation of an integrated communication skills training program for nurses in cancer care in Beijing, China. Nursing research, 56(3), 202-209. http://dx.doi.org/10.1097/01.NNR.0000270030.82736.8c

McCabe, C. (2004 Jan). Nurse-patient communication: an exploration of patients' experiences. Journal of Clinical Nursing, 13(1), 41-49. http://dx.doi.org/10.1111/j.1365-2702.2004.00817.x

Meyer, G., \& Arnheim, L. (2002). The power of two improving patient safety through better physician-patient communication. Family Practice Management 2002;9: 47-60. Family Practice Management, 9, 47-60.

Namdar, H., Rahmani, A., \& Ebrahimi, H. (2009). The Effect of a Skill-Training Model on Nursing Students' Skills in Communicating with Mental Patients. Iranian Journal of Medical Education, 8(2), 323-332.

Reader, T., Flin, R., \& Cuthbertson, B. (2007). Communication skills and error in the intensive care unit. Current Opinion in Critical Care, 13, 732-736. http://dx.doi.org/10.1097/MCC.0b013e3282f1bb0e

Sabet Sarvestani, R., Moattari, M., Nikbakht, N. A., Momennasab, M., \& Yektatalab, S. h. (2013). Chalenges of nursing handover: a qualitative study. Clinical Nursing Research. doi: 10.1177/1054773813508134

Sabzevari, S., Soltani Arabshahi, K., Shekarabi, R., \& Koohpayehzadeh, J. (2006). Nursing Students' Communication with Patients in Hospitals Affiliated to Kerman University of Medical Sciences. Iranian Journal of Medical Education, 6(1), 43-48 [Persian].

Schroeder, S. J. (2006). Picking up the PACE: a new template for shift report. Nursing, 36(10), 22-23. http://dx.doi.org/10.1097/00152193-200610000-00016

Sirota, T. (2007). Nurse/physician relationships: Improving or not? Nursing, 37(1), 52-56. http://dx.doi.org/10.1097/00152193-200701000-00040

Swinny, B., \& Brady, M. (2010). The benefits and challenges of providing nursing student clinical rotations in the intensive care unit. Critical Care Nursing Quarterly, 33, 60-66. http://dx.doi.org/10.1097/CNQ.0b013e3181c8df7c

WHO. (2009). Global standards for the initial education of professional nurses and midwives. World Health Organization.

Xie, J., Ding, S., Wang, C., \& Liu, A. (2012). An evaluation of nursing students' communication ability during practical clinical training. Nurse Education Today, 1-5.

Xie, J., Ding, S., Wang, C., \& Liu, A. (2013). An evaluation of nursing students' communication ability during practical clinical training. Nurse Education Today, 33(8), 823-827. http://dx.doi.org/10.1016/j.nedt.2012.02.011

Zamani, A., Shams, B., Farajzadegan, Z., \& Tabaeian, S. (2003). The viewpoints of clinical faculty members about teaching communication skills to medical students. Iranian Journal of Medical Education, 3(1), 44-49. [Persian]

Zamani, A., Shams, B., \& Moazzam, E. (2004). Communication skills training for physicians as a strategy for enhancing patients' satisfaction: a model for continuing education. Iranian Journal of Medical Education, 4(1), 15-20. [Persian]

\section{Copyrights}

Copyright for this article is retained by the author(s), with first publication rights granted to the journal.

This is an open-access article distributed under the terms and conditions of the Creative Commons Attribution license (http://creativecommons.org/licenses/by/3.0/). 